\title{
Pure Small Cell Carcinoma of the Prostate: A Case Report and Literature Review
}

\author{
Antonio Capizzello ${ }^{a}$ Evangelia Peponi ${ }^{a} \quad N^{2}$ afsika Simou ${ }^{b}$ \\ Dimitrios Ntaskagiannis $^{a} \quad$ Ifigenia Tasiou $^{a} \quad$ Sevasti Kaminab \\ Periklis Tsekeris ${ }^{\mathrm{a}}$

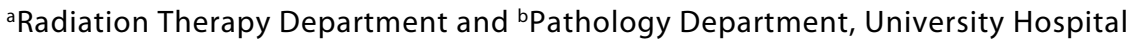 \\ of loannina, loannina, Greece
}

\section{Key Words}

Prostate cancer . Small cell carcinoma . Neuroendocrine differentiation

\begin{abstract}
Primary small cell carcinoma of the prostate (SCPCa) is a rare pathologic entity with unique clinical features and a poor prognosis. We present a case of a patient diagnosed with pure SCPCa treated with a combined chemo-radiotherapeutic approach. Pathological findings showed that the neoplastic cells exhibited positivity for pancytokeratin, synaptophysin, thyroid transcription factor-1 and CD56. Immunostaining for prostate-specific antigen was negative, while serum prostate-specific antigen was within normal limits. We review the available literature to gain additional information about diagnosis, treatment and prognosis of pure SCPCa.
\end{abstract}

\section{Introduction}

Small cell carcinoma of the prostate (SCPCa), also termed neuroendocrine SCPCa, was first described by Wenk et al. [1] in 1977. Its incidence has been estimated at slightly less than $2 \%$ of de novo prostate cancer [2]. Small cell carcinomas usually present together with adenocarcinomas. In some cases, neuroendocrine differentiation occurs sequentially, with an initial pattern of conventional adenocarcinoma, which thereafter presents with focal neuroendocrine differentiation while in recurrence after androgen deprivation therapy [3]. In approximately 35\% of SCPCa cases, the histology is pure SCPCa [4].

The clinical phenotype of SCPCa may be distinguishable from that of typical adenocarcinoma by the common initial presentation of rapidly symptomatic, locally advanced or metastatic disease, occurring frequently with visceral and lytic bone metastases, marked prostatic enlargement and disproportionately low or absent prostate- 
specific antigen (PSA) levels as well as resistance to androgen ablation. These tumors are highly aggressive, with a median survival of 9-10 months and a 5-year survival of less than $1 \%$ [5]. The most typical age at diagnosis is $61-70$ years, although an age range from 24 to 90 years has been reported [2]. Prostatic malignant neuroendocrine cells tend to produce ectopic peptides, with adrenocorticotropic hormone (ACTH) and calcitonin being detected most frequently in serum. Approximately $10 \%$ of small cell carcinoma cases present with paraneoplastic syndromes $[2,6]$.

The most common immunohistochemical markers used to diagnose SCPCa are neuron-specific enolase (NSE), chromogranin A (ChrA), synaptophysin (Syn), CD56 and thyroid transcription factor-1 (TTF-1). Serum ACTH, calcitonin, and parathyroid hormone levels may be elevated regardless of the presence of paraneoplastic syndromes. Tumor markers such as carcinoembryonic antigen (CEA) and cancer antigen 19-9 (Ca 19-9) are also often elevated $[3,6]$.

PSA is a more complicated marker of the disease. Generally, in the case of adenocarcinoma, the disease burden is strongly correlated with the PSA level. However, in patients with mixed tumors or pure SCPCa, the neuroendocrine component does not secrete PSA and, therefore, does not contribute to an elevated PSA level, as PSA reflects the bulk and activity of the nonmalignant elements in the prostate [2].

Given the distinct pathologic and clinical features of the disease and using small cell carcinoma of the lung as a therapeutic model, the treatment for mixed or pure SCPCa consists mainly of a combined multidrug chemotherapy and radiation therapy to improve local control, with radical prostatectomy as an adjunctive therapy in selected cases $[5,7]$. Chemotherapy regimens have been employed with a reported response rate of $60 \%$ without any durable complete remission [8].

We present a case of pure SCPCa treated with a combined chemo-radiotherapeutic approach. Written informed consent was obtained from the patient for the publication of this case report and any accompanying images. Moreover, we review the available literature to gain additional insight into the diagnosis, treatment, and prognosis of this disease.

\section{Case Report}

In May 2007, a 77-year-old man was referred to our hospital with symptoms of urinary retention and dysuria. His past medical history included cardiac insufficiency. On digital rectal examination, the prostate was homogeneously enlarged and diffusely firm. The serum PSA level was within the normal range ( $1.4 \mathrm{ng} / \mathrm{ml}$; range: $0-4)$. He underwent an operation for phimosis, and a catheter was inserted into the urinary bladder. Two weeks after the surgery, the patient was admitted to the urology clinic with macroscopic hematuria and catheter occlusion. A transrectal needle biopsy disclosed a locally advanced, poorly differentiated SCPCa. Computer tomography (CT) of the pelvis showed an enlarged prostate with protrusion into the bladder, while a chest CT showed diffuse lung emphysematous microbullae. A bone scan was negative for metastases. The Ca $19-9$ level was elevated (96 ng/ml; range: 1-37), while the CEA level was within normal limits.

Microscopically, both lobes were diffusely infiltrated by small round neoplastic cells with scanty cytoplasm and a high nuclear to cytoplasmic ratio. The nuclei were hyperchromatic, finely granular with inconspicuous nucleoli (fig. 1). Perineural and neural invasion were focally identified.

Immunohistochemically, the neoplastic cells exhibited positivity for pancytokeratin, Syn, TTF-1 and CD56 (fig. 2). Immunostaining for PSA was negative. The histopathological pattern as well as the presence of positive staining for neuroendocrine markers and the absence of pulmonary lesions 
suggestive of primary pulmonary pathology were the basis for the diagnosis of pure primary SCPCa. The tumor was staged as T2cN0M0 (2002 American Joint Committee on Cancer (AJCC) Staging Criteria).

The patient was admitted to the Radiation Therapy Department of the University Hospital of Ioannina in July 2007. Radiotherapy was given with 4 parallel opposed fields (box technique). The prostate and the regional lymph nodes were included in the irradiation fields. A linear accelerator $(6 \mathrm{MV})$ was used. The daily dose was $1.8 \mathrm{~Gy}$ and the total dose was $63 \mathrm{~Gy}$. In total, 35 fractions were given. After $45 \mathrm{~Gy}$ to the whole pelvis, a boost dose (18 Gy) to the primary site was applied using the shrinkage technique. Six chemotherapy cycles (carboplatin, $450 \mathrm{mg} / A U C$ 5) were also administered every 21 days concomitantly and consequently to radiotherapy. The patient tolerated this treatment well, without any interruption due to acute side effects.

The patient was asymptomatic 6 months after treatment. Serum PSA was within normal limits $(0.2$ $\mathrm{ng} / \mathrm{ml}$ ), while Ca 19-9 remained elevated (69 ng/ml; range: 1-37). Serum SGOT, SGPT and LDH were also elevated. At that time, the patient underwent a chest CT scan because of intensive and irritative cough. The CT scan revealed an enlarged left hilum with lobular atelectasis as well as multiple nodular bilateral lung metastatic lesions. He was hospitalized because of dyspnea and died few weeks later, as his condition continued to deteriorate. The patient died 12 months after the initial diagnosis.

\section{Discussion}

SCPCa is rare, accounting for $0.5-2 \%$ of all prostatic malignancies $[2,3]$. The prostate is one of the more common sites of extrapulmonary small cell carcinomas.

Adenocarcinomatous elements are present concomitantly in at least half of cases, but prognosis does not appear to be affected by the presence of a non-small cell component as, after recognition of the small cell phenotype, in these cases, survival is less than 1.5 years. Additionally, the small cell component may be multifocal and variably distributed through the prostate $[3,7,9]$.

Most patients with SCPCa are symptomatic at diagnosis in comparison with patients with prostate adenocarcinoma alone. Signs and symptoms, in order of frequency, include obstructive, neurologic, and constitutional symptoms, followed by symptoms from paraneoplastic syndromes, bone pain, hydronephrosis, abdominal pain, hematochezia, and hematuria. These tumors have a propensity to metastasize distally to visceral organs, including the liver, bone, lungs, central nervous system, and pericardium, and regionally to the pelvic lymph nodes. The rectum and bladder can be invaded due to local tumor infiltration [2].

The histologic origin of SCPCa remains controversial. Several theories have been proposed over the years. The initial hypothesis was that SCPCa is derived from the neural crest line/amine precursor uptake and decarboxylase cell system, now called neuroendocrine system, a cell lineage that is different from prostatic epithelium [1]. Another theory favors a malignant transformation of normal prostatic neuroendocrine cells. Based on the observation that SCPCa sometimes coexists with adenocarcinoma, it was postulated that SCPCa is the product of a final dedifferentiation of the typical adenocarcinoma according to the model of divergent differentiation [10]. Coexpression of PSA in neuroendocrine cells was viewed as supporting evidence for the prostatic epithelial origin of these cells. Nevertheless, the cells seem to represent postmitotic cells, a fact that makes it unlikely that these cells suddenly start to proliferate and become a highly aggressive small cell carcinoma. Finally, a recent theory proposes a direct origin from a multipotential prostatic epithelial stem cell for SCPCa, based on the lack of immunohistologic characteristics typical of the usual prostatic epithelial cell (PSA 
expression and androgen receptor positivity) and the extremely high MIB-1 labeling index clearly exceeding that of even dedifferentiated adenocarcinomas [11].

The prostatic neuroendocrine cells have regulatory functions and are capable of producing and releasing a wide variety of secretory products like serotonin and various peptides, including the chromogranins, peptides of the calcitonin families, ACTH, the parathormone-related protein, thyroid-stimulating hormone-like peptides, human choriogonadotropin-like peptides, somatostatin, glucagons, CEA, and the bombesin-like peptides $[3,6]$.

NSE, ChrA, TTF-1 and Syn are considered representative neuroendocrine tissue markers that are used in the pathologic diagnosis of SCPCa in addition to a lack of androgen receptor positivity and a lack of PSA [11]. It has also been reported that neuroendocrine SCPCa cells showing an aggressive phenotype exhibit intense staining of vascular endothelial growth factor (VEGF) [12].

The measurement of serum neuroendocrine markers should be useful for diagnosing and monitoring the patients' clinical course, as this constitutes a representative indicator and an objective measure of the neuroendocrine differentiation, reflecting not only the primary tumor cell population but also its associated metastases. NSE and ChrA have been demonstrated as the main serum neuroendocrine markers for the clinical evaluation of SCPCa [6]. Additionally, it has been reported that patients who present with a low serum albumin level and a high serum LDH level at the time of initial diagnosis appear to have inferior survival [5].

Because of the rarity of pure SCPCa, most of our knowledge concerning its diagnosis, treatment and prognosis has been gained from a few single-institution reviews and case reports. Therefore, it is impossible to draw definitive conclusions regarding the most effective treatment of this disease. The published studies assessed cases of pure SCPCa together with cases where SCPCa coexists with adenocarcinoma. The existing and mostly single-institution experience with SCPCa and an analysis of the pure SCPCa cases are summarized in table 1.

The role of hormonal therapy in small cell carcinoma remains controversial. In the setting of mixed histologies, hormonal therapy (by orchiectomy, gonadotropin-releasing agonists, or antagonists with the early addition of antiandrogens) should be used according to stage and treatment regimens. For localized disease, hormonal therapy could be used as an adjunct to radiation therapy. The timing (neoadjuvant or adjuvant) and duration of hormone ablation in those patients are uncertain. Nonetheless, it should not be used as a sole therapy. For metastatic disease, long-term hormonal therapy should be combined with chemotherapy $[2,7]$. In cases of pure SCPCa, hormonal therapy is not recommended, as the prostatic neuroendocrine cells are deprived of androgen receptors [3].

Whether the androgen ablation therapy should be continued or not in patients with adenocarcinoma whose tumors undergo neuroendocrine transdifferentiation is a crucial matter. Considering that prolonged hormonal ablation therapy may enhance the selection and progression of neuroendocrine differentiated, androgen-independent tumor cells through processes of transdifferentiation or clonal selection [6], in combination with the antiandrogen withdrawal effect, it is recommended that the antiandrogens are discontinued before initiation of chemotherapy. 
According to small cell lung carcinoma treatment experience, cisplatin and etoposide are the most commonly recommended agents. A recent phase II trial advocated that the addition of doxorubicin to this regimen caused higher toxicity related to the patients' survival outcome [8]. Cyclophosphamide, vincristine, taxanes and ifosfamide have also been added to cisplatin in various combinations $[2,13]$. Carboplatin combined with etoposide or taxanes has also been administered instead of cisplatin. Regarding irradiation, no exact guidelines for total dose and irradiation volume have been given. Because of the disease propensity for local and pelvic lymph node relapse, the treatment volume should include the pelvic lymph nodes with a dose between 45 and 55 Gy (daily dose $1.8 \mathrm{~Gy}$ ), followed by a boost to the prostate volume reaching in some studies a total dose of 72 Gy [7].

Although in SCPCa locoregional treatment is secondary to systemic therapy, in cases of localized or early SCPCa, several studies suggest that surgical resection with or without external beam radiotherapy should be evaluated further as a treatment strategy for selected patients with nonmetastatic SCPCa, as it may provide better local control and a potential survival benefit when combined with systemic therapy compared with systemic therapy alone $[5,14]$.

In some cases, the diagnosis of SCPCa will be incidental to a coexisting adenocarcinoma upon pathological examination of a prostatectomy specimen. Adjuvant chemotherapy - at least 4 cycles of cisplatin and etoposide - should be added to these patients [2], while adjuvant radiotherapy is implemented at the discretion of the treating physician, based on adverse pathologic features such as involved surgical margins and/or extracapsular extension (pT3a) [7].

Metastatic disease is treated with chemotherapy. Radiation therapy could also have a role in the treatment of patients with SCPCa and metastases. Its role is palliative, as it may control local symptoms such as complications of brain and bone metastases.

Transurethral resection of the prostate may be considered for cases with obstructive voiding symptoms that do not respond to chemotherapy and pharmacologic interventions.

Recently, the neuroendocrine cells became a therapeutic target, which opens additional options for patients with SCPCa. Agents, like somatostatin analogues, neuropeptide-like serotonin and bombesin antagonists, or inflammatory cytokines, like interleukin-6, are under investigation in clinical and laboratory settings. However, trials using somatostatin analogues not only for SCPCa but also for hormone refractory prostate cancer with or without metastases have attained some success without major adverse effects [15]. The expression of the angiogenic factors VEGF and TGF-A in neuroendocrine SCPCa cells may also be used in the diagnosis, follow-up and targeting of specific molecular sites. Additionally, in hormone refractory prostate cell lines, it has been found that VEGF-C promotes survival of cancer cells under oxidative stress by the activation of mammalian target of rapamycin and Akt [12] - a mechanism that could also potentially serve as a novel therapeutic target. 


\section{Conclusion}

SCPCa presents an aggressive tumor histology that is associated with a high diseasespecific mortality. For patients with localized disease, a benefit of the application of local treatment modalities like radiation therapy, in combination with chemotherapy with or without hormonal therapy, seems to be acceptable. Further research may lead to advances in the understanding of the neuroendocrine differentiation in prostate cancer, potential integration of treatment modalities and exploration of novel therapeutic targets that would be translated in improved clinical outcome.

\section{Disclosure Statement}

None.

Table 1. Major single-institution reviews of SCPCa and analysis of pure SCPCa cases

\begin{tabular}{|c|c|c|c|c|c|c|c|c|c|c|}
\hline Study & $\begin{array}{l}\text { Inclusion } \\
\text { period }\end{array}$ & $\begin{array}{l}\mathrm{SCPCa} \\
\mathrm{n}\end{array}$ & $\begin{array}{l}\text { Pure } \\
\text { SCPCa } \\
\mathrm{n}(\%)\end{array}$ & $\begin{array}{l}\text { Stage } \\
\text { III/IV }\end{array}$ & $\begin{array}{l}\mathrm{PSA}, \mathrm{ng} / \mathrm{ml} \\
\text { median (range) }\end{array}$ & $\begin{array}{l}\text { Elevated } \\
\text { PSA }\end{array}$ & Immunostaining & $\begin{array}{l}\text { Chemo- } \\
\text { therapy }\end{array}$ & Additional therapy & $\begin{array}{l}\text { OS, months } \\
\text { median (range) }\end{array}$ \\
\hline $\begin{array}{l}\text { Amato } \\
1992[13]\end{array}$ & - & 21 & $13(62)$ & $100 \%$ & - & $7 \%$ & - & $100 \%$ & ADT: 15 (71\%) & $9.4(1-25)$ \\
\hline $\begin{array}{l}\text { Oesterling } \\
1992[10]\end{array}$ & $\begin{array}{l}1960- \\
1990\end{array}$ & 27 & $18(67)$ & $26(96 \%)$ & - & - & $\begin{array}{l}\text { NSE (+): } 100 \% \\
\text { PSA (+): } 0 \%\end{array}$ & $7 \%$ & $\begin{array}{l}\text { ADT: } 25(71 \%) \\
\text { EBRT: } 15(56 \%) \\
\text { Surgery: } 2(7 \%)\end{array}$ & $17.1(2-90)$ \\
\hline \multirow[t]{2}{*}{$\begin{array}{l}\text { Helpap } \\
1999[11]\end{array}$} & $\begin{array}{l}1994- \\
1998\end{array}$ & 19 & $10(53)$ & $\begin{array}{l}\text { non pure: } \\
3 / 9(33 \%)\end{array}$ & $\begin{array}{l}\text { non pure: } \\
56.4(3.5-146)\end{array}$ & & $\begin{array}{l}\text { non pure: } \\
\text { NSE (+): } 0 \% \\
\text { Syn (+): } 0 \% \\
\text { ChrA (+): } 0 \% \\
\text { PSA (+): } 61.8 \% \\
\end{array}$ & & $\begin{array}{l}\text { non pure: } \\
\text { ADT: } 3 / 9(33 \%) \\
\text { EBRT: } 3 / 9(33 \%) \\
\text { Surgery: } 3 / 9(33 \%)\end{array}$ & $\begin{array}{l}\text { non pure: } \\
12\end{array}$ \\
\hline & & & & $\begin{array}{l}\text { pure: } \\
5 / 10(50 \%)\end{array}$ & $\begin{array}{l}\text { pure: } \\
7.1(0.9-23.6)\end{array}$ & - & $\begin{array}{l}\text { pure: } \\
\text { NSE (+): } 83 \% \\
\text { Syn (+): } 61 \% \\
\text { ChrA (+): } 25 \% \\
\text { PSA (+): } 0 \%\end{array}$ & $0 \%$ & $\begin{array}{l}\text { pure: } \\
\text { ADT: } 3 / 10(30 \%) \\
\text { Surgery: } 1 / 10(10 \%)\end{array}$ & $\begin{array}{l}\text { pure: } \\
7.7(2-12)\end{array}$ \\
\hline $\begin{array}{l}\text { Sella } \\
2000[9]\end{array}$ & $\begin{array}{l}1995- \\
1999\end{array}$ & 18 & $6(33)$ & 100 & $1.6(0-9.5)$ & $0 \%$ & $\begin{array}{l}\text { NSE (+): } 14 / 16(88 \%) \\
\text { [NSE (+) in pure: } 6 / 6] \\
\text { ChrA (+): } 12 / 16(75 \%) \\
\text { [ChrA (+) in pure: } 5 / 6]\end{array}$ & $67 \%$ & $\begin{array}{l}\text { prior: } \\
\text { ADT }(100 \%)\end{array}$ & $6.7(0.02-29.6)$ \\
\hline $\begin{array}{l}\text { Papandreou } \\
2002[8]\end{array}$ & $\begin{array}{l}1992- \\
1999\end{array}$ & 36 & $24(67)$ & $\begin{array}{l}\text { stage IV: } \\
32(89 \%)\end{array}$ & $1.5(0.05-283)$ & $\begin{array}{l}11 \\
(31 \%)\end{array}$ & $\begin{array}{l}\text { ChrA (+): 20/29 (69\%) } \\
\text { Syn (+): 20/27 (74\%) }\end{array}$ & $100 \%$ & $\begin{array}{l}\text { prior: } \\
\text { ADT: } 29(81 \%) \\
\text { EBRT: } 16(44 \%)\end{array}$ & $10.5(7.5-14.3)$ \\
\hline $\begin{array}{l}\text { Asmis } \\
2006[14]\end{array}$ & $\begin{array}{l}1991- \\
2002\end{array}$ & 10 & $5(50)$ & $8(80 \%)$ & - & - & - & $80 \%$ & $\begin{array}{l}\text { ADT: } 3(30 \%) \\
\text { EBRT: } 8(80 \%)\end{array}$ & $9.5(2-16)$ \\
\hline $\begin{array}{l}\text { Spiess } \\
2007[5]\end{array}$ & $\begin{array}{l}1985- \\
2005\end{array}$ & 83 & $30(36)$ & $\begin{array}{l}\text { stage IV: } \\
62(75 \%)\end{array}$ & $10(0.9-603)$ & $0 \%$ & - & $\begin{array}{l}76 \\
(92 \%)\end{array}$ & $\begin{array}{l}\text { ADT: } 39(47 \%) \\
\text { EBRT: } 6(7 \%) \\
\text { surgery: } 3(4 \%)\end{array}$ & $13.1(10.7-17.1)$ \\
\hline
\end{tabular}

$\mathrm{ADT}=$ Androgen deprivation therapy; $\mathrm{PSA}=$ prostate-specific antigen; $\mathrm{EBRT}=$ external beam radiotherapy; $\mathrm{NSE}=$ neuron-specific enolase; ChrA $=$ chromogranin $\mathrm{A} ;$ Syn $=$ synaptophysin. 


\begin{tabular}{r|l|l|l}
$\begin{array}{r}\text { Case Reports in } \\
\text { Oncology }\end{array}$ & $\begin{array}{l}\text { Case Rep Oncol 2011;4:88-95 } \\
\text { DOl: 10.1159/000324717 }\end{array}$ & $\begin{array}{l}\text { Published online: } \\
\text { February 16, 2011 }\end{array}$ & $\begin{array}{l}\text { O 2011 S. Karger AG, Basel } \\
\text { ISSN 1662-6575 } \\
\text { www.karger.com/cro }\end{array}$ \\
\hline
\end{tabular}

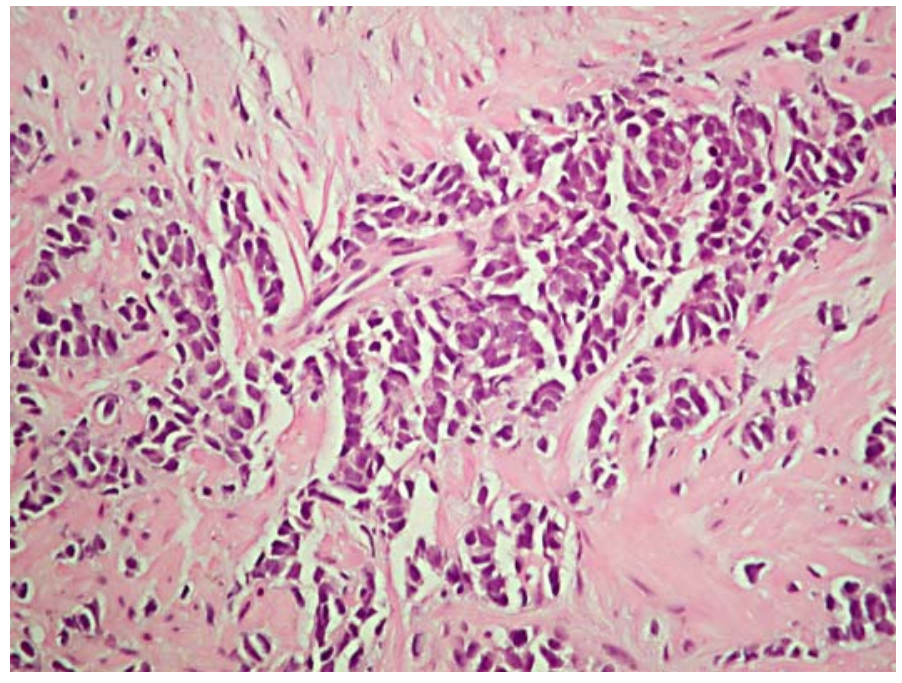

Fig. 1. HE staining (original magnification $\times 400$ ).

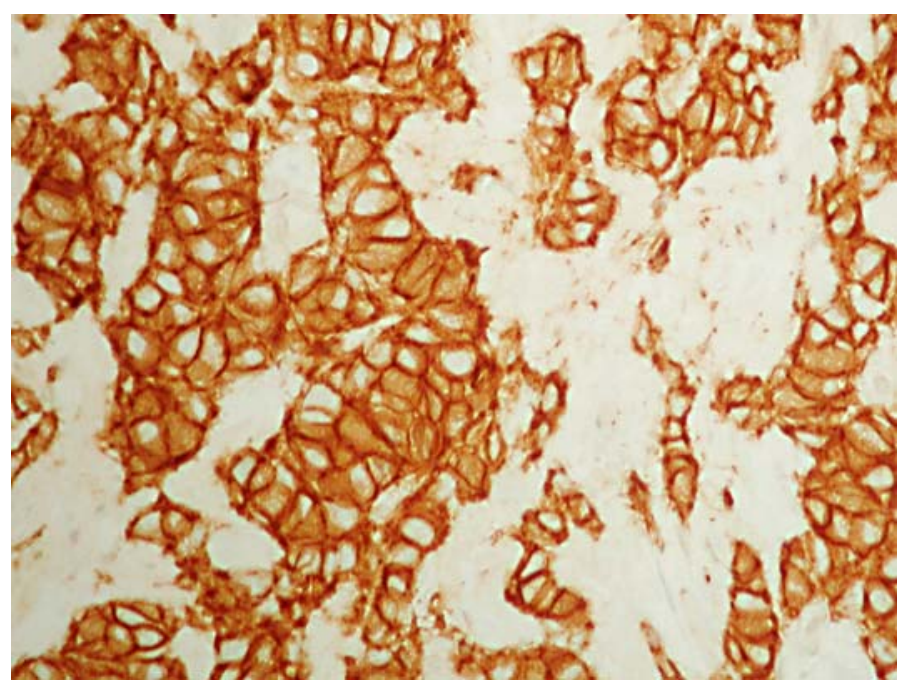

Fig. 2. Immunostaining for CD56 (original magnification $\times 400$ ).

\section{References}

1 Wenk RE, Bhagavan BS, Levy R, Miller D, Weisburger W: Ectopic ACTH, prostatic oat cell carcinoma, and marked hypernatremia. Cancer 1977;40:773-778.

2 Palmgren JS, Karavadia SS, Wakefield MR: Unusual and underappreciated: small cell carcinoma of the prostate. Semin Oncol 2007;34:22-29.

3 di Sant'Agnese PA: Neuroendocrine differentiation in carcinoma of the prostate. Diagnostic, prognostic, and therapeutic implications. Cancer 1992;70(1 suppl):254-268.

4 Petraki C, Vaslamatzis M, Petraki K, Revelos K, Alevizopoulos N, Papanastasiou P, Gregorakis A: Prostate cancer with small-cell morphology: an immunophenotypic subdivision. Scand J Urol Nephrol 2005;39:455463. 
5 Spiess PE, Pettaway CA, Vakar-Lopez F, Kassouf W, Wang X, Busby JE, Do KA, Davuluri R, Tannir NM: Treatment outcomes of small cell carcinoma of the prostate: a single-center study. Cancer 2007;110:1729-1737.

6 Abrahamsson PA: Neuroendocrine differentiation in prostatic carcinoma. Prostate 1999;39:135-148.

7 Stein ME, Bernstein Z, Abacioglu U, Sengoz M, Miller RC, Meirovitz A, Zouhair A, Freixa SV, Poortmans PH, Ash R, Kuten A: Small cell (neuroendocrine) carcinoma of the prostate: etiology, diagnosis, prognosis, and therapeutic implications - a retrospective study of 30 patients from the rare cancer network. Am J Med Sci 2008; $336: 478-488$.

8 Papandreou CN, Daliani DD, Thall PF, Tu SM, Wang X, Reyes A, Troncoso P, Logothetis CJ: Results of a phase II study with doxorubicin, etoposide, and cisplatin in patients with fully characterized small-cell carcinoma of the prostate. J Clin Oncol 2002;20:3072-3080.

9 Sella A, Konichezky M, Flex D, Sulkes A, Baniel J: Low PSA metastatic androgen-independent prostate cancer. Eur Urol 2000;38:250-254.

10 Oesterling JE, Hauzeur CG, Farrow GM: Small cell anaplastic carcinoma of the prostate: a clinical, pathological and immunohistological study of 27 patients. J Urol 1992;147(3 Pt 2):804-807.

11 Helpap B, Köllermann J: Undifferentiated carcinoma of the prostate with small cell features: immunohistochemical subtyping and reflections on histogenesis. Virchows Arch 1999;434:385-391.

12 Muders MH, Zhang H, Wang E, Tindall DJ, Datta K: Vascular endothelial growth factor-C protects prostate cancer cells from oxidative stress by the activation of mammalian target of rapamycin complex-2 and AKT- 1 . Cancer Res 2009;69:6042-6048.

13 Amato RJ, Logothetis CJ, Hallinan R, Ro JY, Sella A, Dexeus FH: Chemotherapy for small cell carcinoma of prostatic origin. J Urol 1992;147(3 Pt 2):935-937.

14 Asmis TR, Reaume MN, Dahrouge S, Malone S: Genitourinary small cell carcinoma: a retrospective review of treatment and survival patterns at The Ottawa Hospital Regional Cancer Center. BJU Int 2006;97:711-715.

15 Koutsilieris M, Mitsiades CS, Bogdanos J, Dimopoulos T, Karamanolakis D, Milathianakis C, Tsintavis A: Combination of somatostatin analog, dexamethasone, and standard androgen ablation therapy in stage D3 prostate cancer patients with bone metastases. Clin Cancer Res 2004;10:4398-4405. 